\title{
Rendimento diário por tarefeiro na colheita de erva-mate
}

\author{
Cristiano Nunes Nesi ${ }^{1}$, Paulo Alfonso Floss² e Dorli Mario Da Croce ${ }^{3}$
}

Resumo - O objetivo do trabalho foi avaliar o rendimento médio diário da atividade de colheita da erva-mate por tarefeiro em ervais cultivados e não cultivados. Inicialmente foram solicitados às ervateiras da região os controles de corte dos seus colaboradores com registro da produtividade individual $\left(\mathrm{kg} \mathrm{homen}^{-1} \mathrm{dia}^{-1}\right)$ nos últimos meses. Com estes dados, considerados 'amostra-piloto', calcularam-se a média e o desvio-padrão em função do tipo de erval (cultivado e não cultivado), determinandose o número mínimo de colaboradores a serem avaliados. Foram amostrados tarefeiros de 11 principais ervateiras do Oeste e Meio-Oeste de Santa Catarina. Por disponibilidade no momento das avaliações, foram avaliados 46 e 44 colaboradores nos sistemas não cultivado e cultivado, respectivamente. Com 95\% de confiança, estimou-se que o rendimento médio amostrado tem um erro máximo de 6,36\% e 4,05\% para os ervais não cultivados e cultivados, respectivamente. 0 rendimento médio de poda de $734,5 \mathrm{~kg} \mathrm{homem}^{-1} \mathrm{dia}^{-1}$ para os ervais cultivados foi significativamente maior em relação aos não cultivados, $535,5 \mathrm{~kg}$ homem ${ }^{-1} \mathrm{dia}^{-1}$.

Termos para indexação: Ilex paraguariensis; amostragem; colheita; produtividade; indústria.

\section{Daily income per worker in the erva-mate harvest}

\begin{abstract}
The aim of this work was to evaluate the average daily yield of the yerba mate harvesting activity per employee in cultivated and non-cultivated herbs. Initially, the herb stores in the region were asked to cut their employees' controls with individual productivity records $(\mathrm{kg} / \mathrm{man} /$ day) in the last months. With these data, considered 'pilot sample', the mean and standard deviation were calculated according to the type of herb (cultivated and not cultivated), determining the minimum number of employees to be evaluated. Workers from 11 main herbaceous plants in the West and Midwest of Santa Catarina were sampled. By availability at the time of evaluations, 46 and 44 employees were evaluated in the non-cultivated and cultivated systems, respectively. With $95 \%$ confidence, it was estimated that the average yield sampled has a maximum error of $6.36 \%$ and $4.05 \%$ for non-cultivated and cultivated herbs, respectively. The average pruning yield of $734.5 \mathrm{~kg} \mathrm{man}^{-1} \mathrm{day}^{-1}$ for cultivated herbs was significantly higher compared to non-cultivated, $535.8 \mathrm{~kg} \mathrm{man}^{-1}$ day $^{-1}$.
\end{abstract}

Index-terms: Ilex paraguariensis; sampling; harvest; productivity; industry.

A cadeia produtiva da erva-mate apresentou diversos avanços tecnológicos nas últimas décadas, mas ainda necessita de muitos estudos e pesquisas na área social que contemplem a relação entre trabalhador e empregador. Sob o ponto de vista econômico, social e ambiental, a atividade ervateira é complexa, especialmente quando se trata da colheita dos ervais. A erva-mate (Ilex paraguariensis A. St. Hil.) é economicamente o principal produto florestal não madeireiro da Região Sul do Brasil. Tem grande importância ambiental, social e econômica para grande número de famílias em suas regiões produtoras (PENTEADO JÚNIOR \& GOULART, 2019).

Até a década de 80 praticamente só existiam os denominados ervais nativos ou em ser. Com a criação do pacote tecnológico para produção de mudas, plantio e manejo para cultura da erva-mate, a produção dos ervais cultivados passa a ser significativa em diversas regiões do estado de Santa Catarina. Desta forma, houve a necessidade de desenvolver técnicas de colheita destes novos ervais e tecnologia para recuperação e manejo dos ervais nativos (DA CROCE \& FLOSS, 1999).

Mazuchowski (1989) distinguiu duas situações características dos ervais: a) erval nativo, formado pela natureza, com intervenção do homem no seu manejo ou seu adensamento; b) erval plantado pelo homem em condições de sombreamento ou pleno sol, consorciado ou solteiro. A principal diferença dos ervais nativos em relação aos cultivados é a baixa densidade, a maior altura das plantas nos ervais nativos que se encontram consorciados com outras espécies arbóreas e/ou com animais. Os ervais cultivados são normalmente plantados em alta densidade, ficam mais homogêneos e apresentam menor altura das plantas, sendo caracterizados pela monocultura. Diante disso, podem existir diferenças nas produtividades e rendimento do trabalhador na colheita entre os tipos de ervais.

Segundo informações do Sindicato da Indústria do Mate de Catanduvas, que congrega 40 indústrias do mate do

Recebido em 30/6/2020. Aceito para publicação em 2/9/2020.

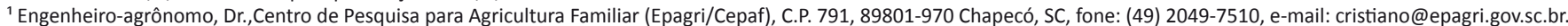

${ }^{2}$ Engenheiro florestal, Dr., Epagri/Cepaf, e-mail: pfloss@epagri.sc.gov.br

${ }^{3}$ Engenheiro florestal, M.Sc., Aposentado Epagri/Cepaf, e-mail: dacroce2015@gmail.com. 
Oeste e do Meio-Oeste de Santa Catariana, são empregados aproximadamente 1.000 funcionários que trabalham na colheita da erva-mate nestas regiões. A colheita se refere à poda da erva-mate e à confecção dos raídos - feixes de ervamate prontos para pesagem e transporte para indústria.

Como na maioria dos casos as indústrias ervateiras remuneram os tarefeiros do corte de erva-mate com salário fixo mais o rendimento diário de colheita, também devem ser levadas em conta as dificuldades de colheita inerentes aos ervais cultivados e não cultivados. Assim, o trabalho teve por objetivo estimar o rendimento médio da atividade de colheita da erva-mate por tarefeiro envolvido na poda de ervais cultivados e não cultivados (nativos) na região Oeste e Meio-Oeste de Santa Catarina.

O trabalho foi realizado pela Epagri/ Cepaf de Chapecó, SC. Inicialmente foram solicitados às ervateiras da região os controles de poda da erva-mate dos seus colaboradores, com registro da produtividade individual ( $\mathrm{kg} / \mathrm{homem} /$ dia) nos últimos três meses. Com estes dados, considerados 'amostra-piloto', calcularam-se a média e o desvio-padrão em função do tipo de erval (cultivado e não cultivado) e definiu-se o número mínimo (n) de indivíduos (Silva, 2004) que seriam avaliados na pesquisa: $n>\left(t_{\delta} . s / e\right)^{2}$ em que ' $n$ ' é o tamanho mínimo de amostras, ' $t_{\delta}$ ' é o quantil da distribuição " $\mathrm{t}$ " na posição $[\delta+(1-\delta) / 2$ ] para o teste bilateral, 's' é o desviopadrão da amostra e 'e' o erro amostral tolerável, calculado como uma proporção da média na amostra observada, definido em $5 \%$ da média observada na amostra piloto. Considerou-se que o tamanho da população de tarefeiros é desconhecido.

As ervateiras foram consideradas homogêneas com relação à produtividade dos seus colaboradores. Desta forma, realizou-se uma amostragem estratificada proporcional, com o número de indivíduos avaliados em cada ervateira dado como uma subamostra proporcional ao número de colaboradores da ervateira. Os colaboradores avaliados foram definidos de forma aleatória por sorteio quando a equipe de pesquisa chegava à propriedade. Em função da distância entre os locais de avaliação, a coleta dos dados foi realizada nos meses de novembro e dezembro. Não houve preocupação em observar o nível tecnológico dos ervais e se o sistema de poda adotado pelas diferentes ervateiras era o mais recomendado ou adequado. Somente foi acompanhada a pesagem para avaliar o rendimento por "tarefeiro". Após a coleta, os dados foram tabulados e estimados o rendimento médio e o desvio-padrão da atividade individual de colheita, além do erro amostral para os dados observados. Foram estimados também os intervalos com $95 \%$ de confiança (IC) para o rendimento médio no corte da erva-mate cultivada e não cultivada:

$$
\text { IC }(\bar{x} ; 95 \%): \bar{x} \pm t_{\frac{a}{2}} \frac{s}{\sqrt{n}}
$$

em que: $X$ é a média observada; $\mathrm{t}_{\alpha / 2}$ : valor crítico do teste t para a confiança desejada e graus de liberdade da amostra; s: desvio padrão da amostra; $n$ é o tamanho da amostra.

A produção diária por colaborador (tarefeiro) se refere às atividades de poda e a confecção do raído. Quando existia entre os tarefeiros trabalhos em equipe, duas ou mais pessoas, a produção do final do dia era dividida pelo número de componentes da equipe. Somente foram utilizados dados de dia completo de trabalho. Os resultados dos controles de cortes fornecidos pelas ervateiras e considerados como a amostra piloto são apresentados na Tabela 1.

Os resultados da colheita no mês de agosto no erval nativo foram considerados discrepantes por apresentar baixo rendimento (baixa média) e grande variabilidade, o que resulta num tamanho de amostra desnecessariamente grande. Assim, o tamanho amostral foi definido sobre o maior valor observado para ervais cultivados, sendo definidos em no mínimo 41 em cada sistema de cultivo. Este número foi dividido proporcionalmente em relação ao número total de cortadores das 11 principais ervateiras da região (Tabela 2 ), avaliandose no mínimo 2 e no máximo 7 cortadores em cada sistema de cultivo e em cada ervateira.

Os rendimentos médios por tarefeiro na poda de ervais nas indústrias ervateiras dos Oeste e do Meio-Oeste de Santa Catarina obtidos na amostragem são apresentados na Tabela 3. Por disponibilidade de tarefeiros no momento da amostragem, foram avaliados 46 funcionários na poda de ervais não cultivados e 44 funcionários para ervais cultivados. Em função deste tamanho de amostra e do rendimento avaliado, estimou-se em $6,36 \%$ e $4,05 \%$ o erro amostral associado às estimativas de cada sistema.

Como era esperado, o rendimento

Tabela 1. Resultados de produtividade dos tarefeiros obtidos a partir dos arquivos das ervateiras em função do sistema de cultivo da erva-mate e do mês de avaliação

Table 1. Results of the productivity of the workers obtained from the archives of the herbaceous plants according to the cultivation system of the yerba mate and the month of evaluation

\begin{tabular}{|c|c|c|c|c|c|c|c|}
\hline \multirow{2}{*}{ Sistema } & \multirow{2}{*}{ Mês } & \multirow{2}{*}{ № } & Média & Desv. Pad & \multirow{2}{*}{$\begin{array}{l}\text { CV } \\
\text { (\%) }\end{array}$} & \multicolumn{2}{|c|}{ n amostral } \\
\hline & & & \multicolumn{2}{|c|}{$\mathrm{kg} \mathrm{homem}^{-1} \mathrm{dia}^{-1}$} & & $e=10 \%$ & $e=5 \%$ \\
\hline \multirow[t]{3}{*}{ Nativo } & junho & 14 & 505,6 & 59,0 & 11,67 & 6,4 & 25,4 \\
\hline & julho & 16 & 481,1 & 27,6 & 20,89 & 1,5 & 6,0 \\
\hline & agosto & 15 & 458,8 & 100,5 & 21,9 & 22,1 & 88,3 \\
\hline \multirow[t]{3}{*}{ Plantada } & junho & 23 & 753,8 & 91,1 & 12,09 & 6,3 & 25,1 \\
\hline & julho & 24 & 668,4 & 64,0 & 9,58 & 3,9 & 15,7 \\
\hline & agosto & 25 & 667,4 & 104,1 & 15,6 & 10,4 & 41,5 \\
\hline
\end{tabular}

№: número de registros (tarefeiros) com dados fornecidos pelas ervateiras; CV: coeficiente de variação amostral em porcentagem; n: número de indivíduos a serem avaliados na amostragem; e: erro amostral tolerável 
Tabela 2. Número de cortadores de erva-mate nas 11 principais indústrias ervateiras das regiões do Meio-Oeste e do Oeste Catarinense

Table 2. Number of yerba mate cutters in the 11 main industries in the Midwest and West regions of Santa Catarina

\section{Ervateira \\ Número de cortadores registrados em ervais plantados}

\section{Número de cortadores} avaliados em cada sistema

\begin{tabular}{|c|c|c|}
\hline 1 & 20 & 3 \\
\hline 2 & 25 & 4 \\
\hline 3 & 20 & 3 \\
\hline 4 & 12 & 2 \\
\hline 5 & 20 & 3 \\
\hline 6 & 50 & 7 \\
\hline 7 & 20 & 3 \\
\hline 8 & 20 & 3 \\
\hline 9 & 22 & 3 \\
\hline 10 & 15 & 2 \\
\hline 11 & 50 & 7 \\
\hline Total & 274 & 41 \\
\hline
\end{tabular}

Tabela 3. Rendimento médio diário (kg/homem/dia) para poda de erva-mate em ervais cultivados e não cultivados observado nos tarefeiros das indústrias ervateiras do Oeste e Meio-Oeste do Estado de Santa Catarina

Table 3. Average daily yield ( $\mathrm{kg} / \mathrm{man} /$ day) for pruning of yerba mate in cultivated and noncultivated herbs, observed in the tasks of the herbaceous industries in the West and Mi$d$ west of the State of Santa Catarin

\begin{tabular}{cccccc} 
Sistema & $\mathbf{n}$ & $\begin{array}{c}\text { e } \\
(\%)\end{array}$ & Média & $\begin{array}{c}\text { Desv. Pad. } \\
\text { Kg homem } \text { dia }^{-1}\end{array}$ & IC (95\%) \\
\hline Não Cultivada & 46 & 6,36 & 535,8 & 115,0 & $(501,6 ; 569,9)$ \\
\hline Cultivada & 44 & 4,05 & 734,5 & 97,8 & $(704,8 ; 764,3)$
\end{tabular}

n: número de indivíduos avaliados na amostragem; e: erro amostral estimado em função dos dados observados; IC = Intervalo de Confiança. médio de poda ( $\mathrm{kg}$ homem ${ }^{-1} \mathrm{dia}^{-1}$ ) para os ervais cultivados foi significativamente maior em relação aos não cultivados. Esta diferença se deve ao grau de dificuldade para poda das ervas, que é maior nos ervais não cultivados em relação aos ervais cultivados.

O rendimento diário da poda de erva-mate em sistema cultivado é significativamente superior ao sistema não cultivado. Esta informação deve ser considerada pelas indústrias ervateiras no momento de remunerar seus tarefeiros.

\section{Agradecimentos}

Os autores agradecem aos proprietários das indústrias ervateiras onde foram realizados os acompanhamentos das pesagens da erva-mate.

\section{Referências}

DA CROCE, D.M.; FLOSS, P.A. Cultura da erva-mate no Estado de Santa Catarina. Florianópolis: Epagri, 1999, 81p. (Epagri, Boletim Técnico, 100).

MAZUCHOWSKI, J.Z. Manual da erva-mate (Ilex paraguariensis St. Hil.). Curitiba: Emater, 1989. 104p.

PENTEADO JÚNIOR, J.F.; GOULART, I.C.G. dos R. Erva 20: sistema de produção para ervamate. Brasília, DF: Embrapa, 2019. 152 p.

SILVA, N.N. Amostragem Probabilística: um curso introdutório. 2. ed, 1. reimpressão. São Paulo: EDUSP, 2004.

\section{Sigo a Egogri nas redes sociajis}
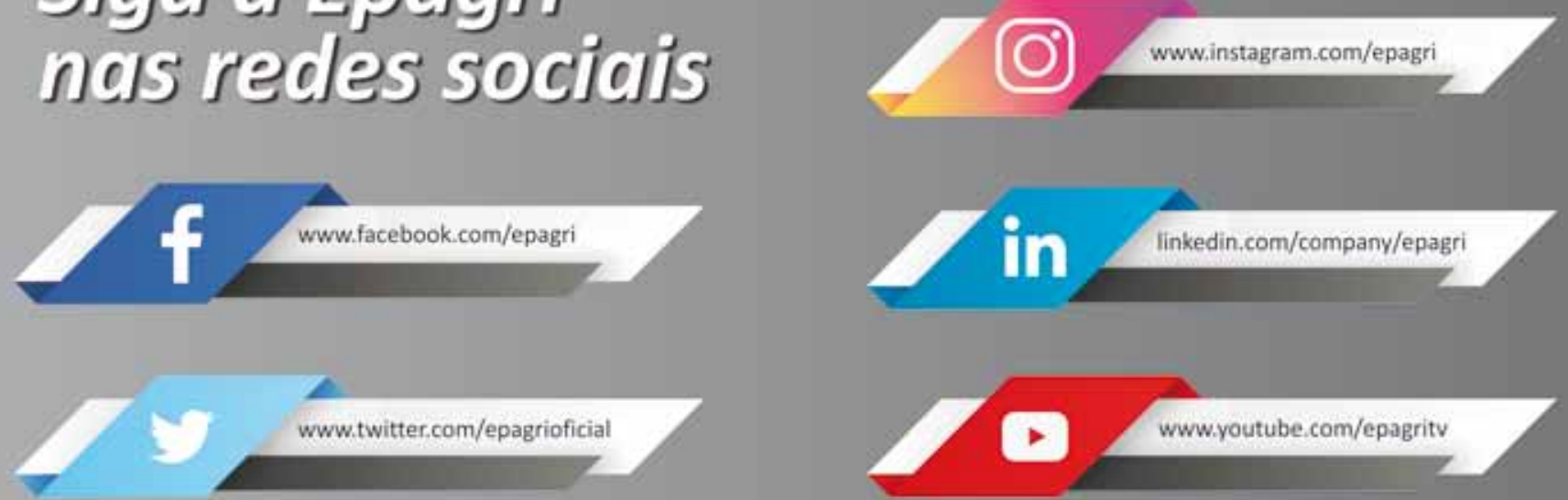